A equipe editorial da Revista Psicologia: Ciência e Profissão comunica a publicação formal de Retratação Parcial para extração de trechos do seguinte artigo:

Guilhon, F., Silva Junior, A. L.; Motta, C.; Moura, A. D.; Uziel, A. P. (2019). Centro de Cidadania LGBT: Memórias e Experiências no Campo das Práticas Psi em Prol da Defesa dos Direitos Humanos. Psicologia:CiênciaeProfissão,39 (n.spe3), 135-145.https://doi.org/10.1590/ 1982-3703003228604

Na página 144 foram publicados erroneamente os endereços pessoais dos (as) autores (as).

Neuza Guareschi

Editora-chefe 


\title{
Centro de Cidadania LGBT: Memórias e Experiências no Campo das Práticas Psi em Prol da Defesa dos Direitos Humanos
}

\author{
Flávio Guilhon ${ }^{1}$ \\ ${ }^{1}$ Universidade do Grande Rio Professor José de \\ Souza Herdy, RJ, Brasil. \\ Carolina Motta ${ }^{3}$ \\ Aureliano Lopes da Silva Junior ${ }^{2}$ \\ ${ }^{2}$ Centro Universitário de Valença, RJ, Brasil. \\ Amanda Duarte Moura ${ }^{3}$ \\ ${ }^{3}$ Universidade Federal Fluminense, RJ, Brasil. \\ ${ }^{3}$ Universidade Federal Fluminense, RJ, Brasil. \\ Anna Paula Uziel ${ }^{4}$ \\ ${ }^{4}$ Universidade do Estado do Rio de Janeiro, RJ, Brasil.
}

\begin{abstract}
Resumo: O presente artigo constitui-se num relato de experiências de profissionais da Psicologia vivenciadas nos Centros de Cidadania LGBT do Programa Rio sem Homofobia, no período em que este programa e seus Centros de Cidadania estiveram plenamente ativos e presentes em diferentes pontos do estado do Rio de Janeiro. Este programa é vinculado à Superintendência de Direitos Individuais, Coletivos e Difusos da então Secretaria de Assistência Social e Direitos Humanos do estado do Rio de Janeiro (SUPERDir/SEASDH) e tem como objetivos gerais o combate às homo, lesbo, bi e transfobias, bem como a promoção da cidadania LGBT. A partir de alguns casos por nós acompanhados, discutimos possibilidades de intervenção que se colocassem ao lado do movimento de ampliação da potência de vida dos(as) usuários(as) do serviço, principalmente pela proposta de intervenções interdisciplinares e articuladas com o contexto da demanda e/ou violação. Desta forma, reiteramos a importância de construirmos o campo das práticas psi atravessado por um trabalho em rede pautado por questões relacionadas aos Direitos Humanos, movimento social e políticas públicas.
\end{abstract}

Palavras-chave: Psicologia, Políticas Públicas, Direitos Humanos, Diversidade Sexual e de Gênero.

\section{LGBT Citizenship Center: Memories and Experiences in the Field of Psi Practices for the Defense of Human Rights}

\begin{abstract}
This article is a narrative of the experiences of psychology professionals working in the LGBT Citizenship Centers of the Rio without Homophobia Programme, in the period in which this program and its Citizenship Centers were fully active and present in different parts of the state of Rio de Janeiro. This program is linked to the Superintendence of Individual, Collective and Diffuse Rights of the Department of Social Assistance and Human Rights of the state of Rio de Janeiro (SUPERDir/SEASDH) and has as general objectives the combat against homo, lesbo, bi and transphobia, as well as the promotion of LGBT citizenship. From a few cases we monitored, we discussed possibilities for intervention that were placed alongside the movement to increase the potency of life of the users of the service, mainly by the proposal of interdisciplinary interventions and articulations with the context of demand and/or violation. In this way, we reiterate the importance of constructing the field of psi practices through a networked work based on issues related to Human Rights, social movement and public policies.
\end{abstract}

Keywords: Psychology, Public Policy, Human Rights, Sexual and Gender Diversity. 


\title{
Centro de Ciudadanía LGBT: Memorias y Experiencias en el Campo de las Prácticas Psi en Defensa de los Derechos Humanos
}

\begin{abstract}
Resumen: Este artículo es un informe de las experiencias de los profesionales de psicología que vivieron en los Centros de Ciudadanía LGBT de Río sin el Programa de Homofobia, durante el período en que este programa y sus Centros de Ciudadanía estuvieron completamente activos y presentes en diferentes partes del estado de Río de Janeiro. Este programa está vinculado a la Superintendencia de Individuos, Colectivos y Difusos de la entonces Secretaría de Asistencia Social y Derechos Humanos del estado de Río de Janeiro (SUPERDir/SEASDH) y tiene como objetivos generales la lucha contra el homo, lesbo, bi y transfobías, así como la promoción de la ciudadanía LGBT. Con base en algunos casos que hemos seguido, discutimos las posibilidades de intervención que se colocarían junto con el movimiento para aumentar el poder de servicio de los usuarios del servicio, principalmente debido a la propuesta de intervenciones interdisciplinarias y articuladas con el contexto de demanda y / o violación Por lo tanto, reiteramos la importancia de construir el campo de las prácticas psi atravesadas por una red basada en temas relacionados con los Derechos Humanos, el movimiento social y las políticas públicas.
\end{abstract}

Palabras clave: Psicología, Políticas Públicas, Derechos Humanos, Diversidad Sexual y de Género.

\section{Introdução}

Este artigo constitui-se num relato de experiências de profissionais da Psicologia vivenciadas nos Centros de Cidadania LGBT do Programa Rio sem Homofobia, entre 2011 e 2016, período em que este programa e seus Centros de Cidadania estiveram plenamente ativos e presentes em diferentes pontos do estado do Rio de Janeiro. Este programa é vinculado à Superintendência de Direitos Individuais, Coletivos e Difusos (SUPERDir) da então Secretaria de Assistência Social e Direitos Humanos (SEASDH) ${ }^{1}$ e tem como objetivos gerais o combate às homo, lesbo, bi e transfobias, bem como a promoção da cidadania LGBT $^{2}$. Naquele período, já passado, o Rio sem Homofobia contava com financiamento para manter todos seus serviços funcionando adequadamente, em um cenário social e político completamente diverso do atual, de crescente conservadorismo ${ }^{3}$, que tem colocado em xeque as mais diversas políticas sociais construídas ao longo das últimas três décadas, a partir do perí- odo de redemocratização do país. Aqui relataremos memórias extremamente afetadas de nossas práticas, as quais afirmamos enquanto uma tarefa política de luta e resistência.

A criação dos Centros de Cidadania LGBT no estado do Rio de Janeiro foi possível a partir da construção coletiva de um programa voltado ao público LGBT, com início em 28 de junho de 2007, com o lançamento da Câmara Técnica (Decreto $\left.n^{\circ} 40.822 / 07\right)$, que cria o Programa Rio sem Homofobia (RSH). As propostas e ações elaboradas por esta câmara foram discutidas e aprovadas na $1^{\text {a }}$ Conferência Estadual de Políticas Públicas e Direitos Humanos para LGBT (2008) e passaram a definir tanto as estratégias de implantação quanto as ações a serem desenvolvidas.

Inspirado no Programa Brasil sem Homofobia, lançado pelo Governo Federal em 2004, o RSH foi inaugurado em 2010 como sua versão estadual (Aguião, 2018) e integrava a SUPERDir junto com o Centro de Promoção da Liberdade Religiosa \& Direi-

\footnotetext{
${ }^{1}$ Atual Secretaria de Estado de Direitos Humanos e Políticas para Mulheres e Idosos (SEDHMI).

${ }^{2}$ Ainda que tivesse apenas o termo Homofobia em sua denominação, este era usado como um termo guarda-chuva para todo tipo de violência e/ou violação sofrida pela população LGBT. Por mais que tal denominação possa ser passível de crítica, na prática as atividades do Programa não se restringiam às homossexualidades como também à época denominações como a atual LGBTfobia não eram tão disseminadas.

${ }^{3}$ Para uma discussão mais detalhada sobre o Programa Rio sem Homofobia ver Carrara, Aguião, Lopes e Tota (2017) e, mais especificamente, acerca do desmonte e crítica a tal Programa, ver Cassal (2018).
} 
tos Humanos (CEPLIR), criado posteriormente, em 21 de janeiro de $2013^{4}$.

O lançamento do Rio sem Homofobia em 2011 contou com dois serviços, o Disque Cidadania LGBT e o primeiro dos quatro Centros de Referência e Promoção da Cidadania LGBT do estado do Rio de Janeiro, que a partir de 2012 passaram a ser chamados de Centro de Cidadania LGBT. A Universidade do Estado do Rio de Janeiro (UERJ) esteve presente desde o início, colaborando com o processo de seleção de profissionais e a montagem do serviço. Para constituir esta política pública, além da parceria com a universidade, o movimento social esteve presente, ao emprestar suas principais lideranças para o poder executivo ${ }^{5}$.

O Disque Cidadania LGBT, lançado em paralelo, funcionava como um serviço telefônico gratuito que recebia demandas de LGBT, familiares e amigos discriminados por homofobia e correlatas, que em seguida eram encaminhadas para um dos Centros de Cidadania LGBT, de acordo com seu local de moradia. Assim, o Disque Cidadania LGBT constituiu-se como uma das principais portas de entrada aos Centros. O número telefônico deste serviço era divulgado de forma destacada no prédio da Central do Brasil, local de grande visibilidade e afluência maciça de pessoas na cidade do Rio de Janeiro.

Já os Centros de Cidadania LGBT ofereciam serviços de orientação jurídica, social e psicológica para o público LGBT, seus familiares e amigos em situação de violação de direitos, além de se constituírem enquanto espaços de irradiação de informações e mobilização em políticas públicas de combate à homofobia e promoção da cidadania, como versaremos na sequência. Este artigo pretende, então, pôr em análise o serviço desenvolvido à época, nas vozes de pessoas que ocuparam lugares de técnicos(as), estagiários(as), bem como de supervisão e acompanhamento da equipe e do Programa como um todo.

\section{Centros de Cidadania LGBT}

Ainda que as pessoas pudessem chegar aos Centros de Cidadania LGBT por diferentes caminhos, como através de encaminhamento do Disque 100, do Governo Federal, ou mesmo pelo Fale Conosco do site do Rio Sem Homofobia, o mais comum era tanto através do Disque Cidadania LGBT, como através do comparecimento direto a cada um dos Centros, o que era nomeado, neste caso, como demanda espontânea.

Ao acessarem diretamente um dos quatro Centros, as pessoas eram acolhidas, recebiam as primeiras orientações e, após ser protocolado, o caso era direcionado pela coordenação a algum/a profissional da equipe interdisciplinar ${ }^{6}$, que passava a ser, a partir daquele momento, sua(seu) técnica(o) de referência. As estratégias utilizadas para se iniciar o acompanhamento poderiam variar tanto de acordo com o Centro quanto de acordo com a disponibilidade de profissionais para acompanhar um caso.

A abordagem inicial dos atendimentos era pautada no acolhimento, onde se definiam a orientação e o encaminhamento de usuárias(os) à rede de serviços da forma mais rápida possível, assim como preconizam programas que inspiraram e balizam o Rio sem Homofobia, como o Brasil sem Homofobia (2004) e o Plano Nacional de Direitos Humanos - PNDH III (2010). Entretanto, no decorrer da trajetória do serviço, este caminho foi sendo redesenhado. Ao reconhecer e debruçar-se sobre experiências, identidade

${ }^{4}$ Como registra Sílvia Aguião (2018), em boletim divulgado em 2007, a SUPERDir afirmava que “iniciou suas ações de combate à discriminação e promoção da cidadania junto à população GLBT (gays, lésbicas, bissexuais, travestis e transexuais); pessoas discriminadas por estado de saúde (HIV-Aids, tuberculose e hepatites); comunidades de religiões de matrizes africanas; comunidade judaica e outras populações discriminadas em razão de sua nacionalidade, origem, religiosidade, além das intolerâncias correlatas e das múltiplas formas de discriminação". Deste leque de atuações, seu carro-chefe sempre foi o Programa Rio sem Homofobia e, em menor grau, a atuação no combate à intolerância religiosa.

${ }^{5}$ Embora não seja o tema deste trabalho, é importante marcar a singularidade da captura, pelo Estado, dos movimentos sociais. Várias lideranças foram compor os quadros do Estado, causando enormes dilemas. Oportunidade que se apresentava fundamental na conquista de direitos e crítica da forma como o Estado em geral se posiciona frente aos direitos LGBT, naquele momento parte do movimento social passou a ser formulador e executor da política, com todas as tensões que este deslocamento provocou.

${ }^{6}$ Esta equipe interdisciplinar era formada por profissionais psicólogos(as), assistentes sociais e advogados(as), bem como por estagiários/as destas áreas que eram estudantes de graduação da UERJ. Através de um convênio entre SEASDH e UERJ, foi criado em 2010 o Laboratório Integrado em Diversidade Sexual e de Gênero, Políticas e Direitos (LIDIS), que era o responsável pela parceria técnica entre o Programa Rio sem Homofobia e a universidade, de modo que a seleção e supervisão acadêmica de estagiários/as ficava a cargo de professores(as) ligados(as) aos LIDIS. A equipe interdisciplinar contava ainda com um/a coordenador(a) do Centro de Cidadania designado(a) pela SUPERDir e que era alguém advindo do movimento social. Ainda que as relações entre academia, movimento social e Estado pudessem ser em alguns momentos tensas, podemos afirmar que na maior parte das vezes ela foi de efetiva parceria e diálogo, principalmente nos Centros de Cidadania LGBT, já que ali o funcionamento dos CCs e o atendimento ao público LGBT se sobrepunha a possíveis tensões políticas. 
e demandas da população LGBT, como um serviço específico, os Centros de Cidadania ofereciam uma verdadeira noção (macro) de comunidade (Anderson, 2008) da qual ele/a poderia fazer parte, potencializando seus(as) (micros) territórios existenciais (Alvarez \& Passos, 2009). Se por um lado era através de uma violação ou reivindicação que um/a usuário/a chegava ao serviço, por outro este era apenas o início de um processo que passava tanto por sua plena legitimação enquanto sujeito, como por certa pedagogização em torno de noções como cidadania, direitos, população LGBT, orientação sexual, identidade de gênero, entre outras.

A mudança nestas prerrogativas que tradicionalmente regem um serviço da rede de saúde e/ou assistência possibilitou a realização de uma escuta mais livre, menos preocupada com o tempo cronológico e mais interessada em seus efeitos, valorizando, deste modo, suas narrativas, falas, choros, risos e silêncios, possibilitando a construção de um território subjetivo no qual suas existências pudessem ser cultivadas, cuidadas, olhadas e valorizadas. Talvez ali fosse possível ensejar "outras formas de prazer, de relações de coexistências, de laços, de amores, de intensidades", como propõe Foucault (1979, p. 235). E é justamente sobre tais processos de singularização que relataremos a seguir. Pelo fato de se tratar de um serviço direcionado ao público LGBT, talvez a preocupação que pudesse envolver a exposição de suas vivências em outros serviços se apresentasse menor, situação que aumentava a possibilidade de trocas entre a equipe técnica e o público acompanhado.

\section{Processos de singularização nas práticas dos Centros de Cidadania LGBT: alguns casos e causos}

Entre as dinâmicas do trabalho desenvolvido nos Centros de Cidadania LGBT estavam as reuniões de equipe. Neste espaço discutíamos o funcionamento do serviço, dificuldades e desafios de construir uma política pública naqueles moldes, mas também casos pensando atravessamentos, entraves e formas de acompanhamento de modo interdisciplinar.
É sobre estes casos que o texto agora se debruça, tentando evidenciar as diversas linhas do rizoma que constituía o trabalho, os efeitos daqueles encontros que se desdobram em outros, em rede, mais ou menos esgarçada, em novos nós e fios que se teciam entre e com as pessoas envolvidas.

\section{Mabel$^{7}$ : uma vivência possível para além das tramas da Saúde Mental}

Negra, trans, pobre, de aparência frágil, olhar doce e jeito meigo, Mabel chega à equipe e encanta todos com quem conversa. Tivemos conhecimento do seu caso, quando a equipe é notificada, em meados de 2011, sobre a internação de Mabel em uma instituição psiquiátrica do estado por ingestão de diversos medicamentos de uma só vez. Apesar deste ter sido o momento que a equipe recebeu o seu caso, Mabel já era conhecida de alguns profissionais da equipe e antes mesmo da estruturação oficial dos Centros de Cidadania LGBT já se ouvia falar sobre ela. Com os dias de sua internação se estendendo, somos informados que, a pedido de uma profissional da assistência que trabalhava naquela instituição, Mabel passara a ocupar a ala masculina, tendo suas unhas cortadas e com previsão de cortarem seus cabelos. As violações que ela sofria eram evidentes e mantivemos contato direto com os(as) profissionais que a acompanhavam a fim de assegurarmos seus direitos e sua integridade.

Após alguns meses, Mabel recebeu alta e voltou a frequentar os espaços do Centro de Cidadania, onde passou a ter novos(as) técnicos(as) e estagiários(as) de referência. Diante do vínculo que estava sendo construído, Mabel retorna com mais frequência, aparecendo sempre de maneira inesperada no final de algumas tardes. Nesses encontros, trazia notícias de seus familiares que residiam em Minas Gerais, contava-nos sua história de vida, os vários cursos que fez no Rio de Janeiro, sua dificuldade em se relacionar com as pessoas e questões de suas internações. No entanto, um dos temas mais presente era a partilha de sua angústia em relação à espera da cirurgia de redesignação sexual ${ }^{8}$. Mabel estava inserida no Programa Transexualizador do Hospital Universitário

\footnotetext{
${ }^{7}$ Todos os nomes são fictícios.

${ }^{8}$ Também conhecida como cirurgia de transgenitalização, constitui-se como um procedimento cirúrgico para reconstrução da neovagina em mulheres trans e neofalo em homens trans. O termo redesignação sexual está presente na Portaria no 2.803/13, que dispõe e regula o chamado Processo Transexualizador no Sistema Único de Saúde (SUS), porém este tipo de procedimento também vem sendo chamado de cirurgia de afirmação do gênero (WPATH, 2012). Para uma maior discussão sobre o acesso a tais cirurgias e as demandas das pessoas trans à atenção à saúde pública no contexto brasileiro ver Almeida e Murta (2013), Teixeira (2017) e Rocon, Sodré, Zamboni, Rodrigues e Roseiro (2017).
} 
Pedro Ernesto (HUPE) da UERJ havia quatro anos e, segundo seu relato, a inserção se deu de forma tranquila, já que não havia muita procura para tal procedimento à época. No referido Programa, a usuária tinha assegurado seu tratamento de hormonização e recebia, assim como as outras pessoas trans, atendimento psicológico, endocrinológico e psiquiátrico. No entanto, a realização efetiva de sua cirurgia era discutida com atenção entre as equipes que a acompanhavam devido à sua questão com a saúde mental. O laudo psiquiátrico que tal Programa exigia para as cirurgias de redesignação sexual ainda estava pendente, no caso de Mabel, já que ela não tinha um diagnóstico definitivo, fechado, e se investigava possíveis traços de esquizofrenia. Por conta do quadro originado antes mesmo de sua chegada ao Rio de Janeiro, fazia uso contínuo de remédios psiquiátricos.

Durante um dos nossos encontros, Mabel compartilha com mais detalhes o episódio de surto vivenciado enquanto trabalhava num salão de beleza em seu estado de origem. Relata ter tido um acesso de raiva e agrediu uma cliente, tendo recebido à época, de fato, o diagnóstico de esquizofrenia, originando uns dias de internação em um manicômio judiciário da cidade. Tal fato é complementado por Mabel com a informação de que ela havia sido presa, em outro momento, por uso/porte de drogas em sua cidade natal.

Esses episódios deixavam dúvidas nas equipes que a acompanhavam sobre seu "preparo psicológico" para lidar com a cirurgia e com todo o complexo pós-operatório. Seu histórico de transtorno mental do tipo esquizofrênico, sua mínima rede social e suas precárias condições financeiras, psíquicas e emocionais de arcar com os procedimentos pós-cirúrgicos deixavam dúvidas sobre como proceder com ela.

Ainda no decorrer dos nossos encontros, surgiram outras demandas como o processo de retificação do registro civil junto à Defensoria Pública ${ }^{9}$ que, assim como sua cirurgia, era constantemente reavaliado.

Quando questionada sobre o que ela pensava que seria a maior mudança em sua vida após a cirur- gia, Mabel dizia que, caso houvesse novas internações, ela poderia ficar na ala feminina sem qualquer impedimento. Tal afirmação nos faz pensar sobre o quão institucionalizada era sua experiência existencial. Mabel tinha sua rotina da semana orientada pelos serviços que a acompanham e uma experiência de trânsito territorial - e existencial - a partir das instituições públicas que lidavam com seu caso. Por isso, os finais de semana eram os momentos mais críticos e o período em que ocorriam algumas de suas internações de emergência.

Mabel nos fazia pensar sobre a questão da saúde mental e o processo transexualizador para muito além do diagnóstico de disforia de gênero ${ }^{10}$. Ao nos posicionarmos contrariamente à patologização das identidades trans, problematizamos a unicidade de um saber biomédico que contribui para a patologização da vida e valida o chamado transtorno de identidade de gênero (atualmente reconhecido como disforia de gênero) que marca as pessoas trans como anormais e que, de alguma forma, precisam ser curadas, sem nos atentarmos para o entorno social e emocional que compõe (com) essas pessoas. Como bem argumentam Bento e Pelúcio (2012), tais práticas reverberam em outras instâncias da vida da pessoa, pois "embora o DSM seja um documento de caráter psiquiátrico, ele consegue se materializar em políticas do corpo nos programas de identidade de gênero e em políticas de Estado, uma vez que compartilha com os outros saberes as mesmas bases fundacionais definidoras do gênero" (2012, p. 575).

\section{Homofobia na escola: intervenções (im) possíveis para tecer redes de cuidado}

Dimitri chega ao serviço demandando processar judicialmente uma professora que, diante da turma, profere a seguinte afirmativa: "não sente do lado de Dimitri, porque ele é viado". O conteúdo desta frase desencadeou memórias e lembranças, especialmente as relacionadas à sua família, para quem sua homos-

${ }^{9}$ À época, a retificação de nome civil para pessoas trans passava pela abertura de um processo jurídico, que poderia ser feito a partir da Defensoria Pública. Ressaltamos que o Núcleo de Defesa dos Direitos Homoafetivos e Diversidade Sexual (NUDIVERSIS), da Defensoria Pública do Rio de Janeiro, sempre foi um grande parceiro tanto do Programa Rio sem Homofobia como da população trans de modo geral, por ser uma instituição que tomou a frente neste processo de retificação de nome civil para pessoas trans. Para uma maior análise deste processo, ver Freire (2016). Desde março de 2018, com a decisão do Supremo Tribunal Federal (STF) e regulamentação do ano anterior do Conselho Nacional de Justiça, ficou permitida a retificação do nome civil nas certidões de nascimento e casamento para maiores de 18 anos diretamente nos cartórios do país, sem a necessidade de qualquer laudo médico, cirurgia de redesignação sexual ou decisão judicial.

${ }^{10}$ Para maiores discussões sobre a complexidade e resistências à patologização de pessoas trans, ver Bento e Pelúcio (2012), de Jesus (2016) e a Resolução nº 01/2018 do Conselho Federal de Psicologia - CFP (2018). 
sexualidade se apresentava como algo vergonhoso e pecaminoso, o que foi comprometendo seu lugar nas relações familiares e comunitárias. A primeira intervenção neste sentido veio de sua mãe, que sinalizou para ele quando ainda era uma criança que "escola não é lugar de viado". Porque ser "viado" o impedia de ocupar um lugar tanto na família quanto escola, resolveu sair de casa e iniciar uma viagem em busca de um lugar onde pudesse, de fato, existir.

As histórias de Dimitri sinalizam duas importantes questões. Se, por um lado, percebemos a dificuldade que os familiares apresentam quanto à homossexualidade de seus filhos e filhas; por outro, evidencia-se o impacto subjetivo na trajetória de seus filhos e filhas, considerando que essa dificuldade se materializa na fragilização dos vínculos afetivos, na prática de violência (física, psicológica, simbólica, afetiva, patrimonial e sexual) e na produção de enorme sofrimento.

No caso de Dimitri, as repercussões se materializavam na dificuldade de se colocar no mundo, na mentira para si e para os outros, na manutenção de seus amores e sexualidade na clandestinidade, uma vez que tomou para si sua homossexualidade como algo de que deveria se envergonhar:

eu não era aceito pelo meu pai, que nem me olhava... minha mãe fingia que não via nada e eu cresci assim, sozinho, sem ninguém, e achando que tudo o que eu sentia era pecado... por isso me refugiei na igreja fazendo tudo o que era possível, tentava ser o melhor de tudo, um exemplo na igreja, para não pensar em mim, e sempre achava que estava sujo e que era indigno de ser amado.

Ao chegar ao Centro de Cidadania LGBT, Dimitri demandava algo que um processo judicial não traria: a restituição de aspectos e partes de sua vida que foram perdidas e a possibilidade de ser amado por sua família. Se por um lado havia a violência cometida pela professora em sala de aula, que ele apresentava como encomenda, e que era passível de representação judicial, por outro havia uma demanda que se relacionava com a possibilidade de estar no mundo de forma mais autônoma e potente, a partir da construção de uma homossexualidade que não o inscrevesse no mundo através da anormalidade ou pecado, mas enquanto vivência possível e saudável, outorgando-lhe a sensação de pertencimento.
Os técnicos que atenderam Dimitri perceberam que poderiam ir além de uma prática denuncista, trazendo a discussão para a escola, tratando o assunto de forma aberta com alunos, professores e direção da escola, apostando na construção de uma articulação em rede, e na potência desse caminho para abordar a questão e construíram uma intervenção em dois movimentos concomitantes: o acompanhamento individual de Dimitri, no sentido de colocar em análise sua relação com a homossexualidade e uma ação de educação e sensibilização junto à escola, na qual a situação de violação de direitos ocorrera.

Por não se sentir pertencente ou reconhecido nos locais por onde passou, circulou por todo o Brasil, sem conseguir se enraizar. Vivenciou sua homossexualidade de modo clandestino, sem construir relacionamentos estáveis, ou fugindo dos homens que queriam se relacionar de modo mais sério: "eu sempre achava que ninguém queria estar comigo, me sentia inadequado, que estavam querendo me enganar, na verdade, eu cresci acreditando que não merecia ser amado, porque o modo como eu amava era pecado". Fez diversas tentativas de retorno à escola, sem conseguir êxito. No momento está namorando, e diz não se sentir bem quando está com a família dele: "é estranho eu estar no meio de uma família que me aceita enquanto a minha nunca me aceitou". E continua:

foi ele quem me incentivou a voltar a estudar, é ele quem está ao meu lado, me tirando da cama, quando perdi a vontade de viver depois do que aconteceu na escola, foi ele quem ligou e me trouxe até aqui, é ele quem fala todo dia que eu tenho que ser mais forte que tudo isso que aconteceu, se não fosse ele, eu não estaria aqui, já teria saído do emprego e ido embora, como sempre faço.

Após três meses, conseguimos apresentar ao Dimitri outra possibilidade de intervenção, que não apenas a de abrir um processo contra a professora. Houve uma reunião com os técnicos, a coordenadora pedagógica, a diretora e duas representantes do Centro Municipal de Referência de Educação de Jovens e Adultos (CREJA), na qual foi apresentada a situação de homofobia cometida contra Dimitri e como isso o afetara, ao ponto dele cogitar abandonar a escola, o que já acontecera antes. Diante disso, a coordenação do CREJA relatou que a postura da professora já ocasionou outros problemas, mas por falta de outro pro- 
fessor, esta profissional continuaria lecionando até o final do ano letivo de 2011. Propusemos então a realização de uma atividade junto à sua turma para discutirmos homofobia e os impactos da violência na vida das pessoas e percebemos um brilho em seu olhar e o vislumbre da possibilidade de sentar-se novamente naquela sala, mas ocupando um outro lugar.

Combinamos dia e horário para a realização da atividade e no dia aprazado chegamos à escola e fomos informadas que a professora, ao saber da atividade, dispensou a turma. Apesar do visível constrangimento e indignação da coordenadora pedagógica, conseguimos pensar numa estratégia para contornar a situação. Realizamos a atividade de forma ampliada, juntando as turmas da escola.

A atividade, sob responsabilidade dos técnicos do Centro de Referência (CR), consistiu em uma dinâmica em que cada pessoa recebe uma etiqueta na qual está escrita uma palavra ou uma frase: "eu bato em minha mulher", "eu apanho do meu marido", "sou um morador de rua", "sou uma prostituta", "sou um policial", "sou uma professora", "sou um alcoolista", "estou desempregada”, "sou pai adolescente”, "sou machista”, "sou um político", "sou gay", "sou transexual", "eu sou travesti”, "sou HIV +", "sou mãe adolescente”, "sou lésbica", "sou candomblecista", "sou estuprador". Ao circularem pelo espaço, as pessoas esboçavam reações sobre as quais se conversou na sequência.

Entre professoras e alunos, cerca de quarenta pessoas participaram da atividade na qual discutimos estereótipos, preconceitos e exclusão e como essas violências produzem sofrimento, adoecimento e, em algumas vezes, a perda da vontade de viver; discutimos os impactos da homofobia na vida das pessoas, apresentando dados e circunscrevendo esta discussão no campo dos Direitos Humanos.

$\mathrm{Na}$ continuidade, em função de uma parceria com o grupo Arco-Íris de Cidadania LGBT, foi apresentado o Projeto "Entre Laços", que trabalha com Teatro do Oprimido. O esquete apresentava algumas cenas de homofobia no ambiente escolar vividas no cotidiano de um rapaz gay e uma moça lésbica, onde a discriminação e o despreparo dos profissionais da educação comprometiam a vinculação dos personagens com a escola. Após a situação encenada, o público entrava em cena tentando achar soluções para aquelas situações-problema.

O debate foi rico, com opiniões divergentes e convergentes. Apareceram falas interessantes demons- trando que existe uma diferença entre lidar com certas situações dentro e fora de casa.

Dimitri conseguiu sentir-se restituído frente aos colegas de turma e frente à vida. Foi possível outro modo de estar diante do mundo, foram lançadas novas existências para serem habitadas e vivências passíveis de serem vividas. O que emerge quando se rompe com a lógica da abjeção dos corpos e da invisibilidade das vidas infames, materializando corpos e ampliando vivências através do fortalecimento da potência de vida.

\section{Psicologia e políticas públicas na diversidade sexual e de gênero}

Clínica, escola, criação de redes. Era neste entre que a Psicologia do RSH se colocava e se deslocava. Talvez uma pista seja pensar nossa atuação na perspectiva de uma clínica ampliada (Campos, 2012). Agentes coletivos de enunciação que somos, ao nos apropriarmos do regime de produção de sentidos, criamos subjetividades e os meios nos quais existem (Coimbra, \& Nascimento, 2007), o RSH foi um espaço de troca e criação.

Ainda iniciamos ali um trabalho de construção de redes, no qual o Centro de Cidadania se assumia como um serviço especializado e, portanto, potente na formação de diversas outras instituições, no que dizia respeito a questões de gênero e sexualidade. No entanto, não se fechava em especialismos e fazia-se vivo nos diversos territórios que habitava. Mesmo que não fizéssemos diretamente tal discussão, construíamos na prática um trabalho de matriciamento a partir da ampliação da escuta e possibilidades de atuação que um(a) usuário(a) nos trazia.

A Psicologia se encontra com o Direito, como o pedido de Dimitri formulava. As leis têm efeitos na vida coletiva, mas em letras frias na qual um comportamento, ou ausência dele, pode representar apenas a escolha de não arcar com as consequências penais. $\mathrm{O}$ caso de Dimitri é apenas um exemplo de um caso que não ficou na via judicializante, em uma esfera individual e privada, cujos efeitos poderiam ser respostas já esperadas por ele. Mas quão potencializadoras seriam essas respostas? A aposta foi em um trabalho de construção coletiva, compartilhada. Seus efeitos estão em movimentos e movimentações pessoais e coletivas. Acreditamos que o trabalho tenha fortalecido Dimitri para enfrentar outras possíveis situações de homofobia ou discriminação, principalmente naquela escola, 
bem como certas crenças puderam ser postas em questionamento gerando reflexões coletivas sobre aquela realidade. No Natal, ele ligou dizendo que continuava na escola e que havia ficado muito feliz com o desfecho que se deu ao caso.

A Psicologia se via atravessada, interpelada pela Medicina, nos processos de patologização da transexualidade e aqui nas negociações em torno do cuidado com a Mabel. A intervenção com outros profissionais sublinhava a vida da Mabel para além da suspeita da sua esquizofrenia. Estabelecer espaços de troca na escola, no hospital é imprescindível para a transformação de todos envolvidos. Mas a Psicologia também emprestava seu corpo como agentes coletivos que somos, para tecer e fortalecer as redes. E promover outras linhas - de fuga.

Diante do contexto de movimentação que caracterizava o funcionamento dos Centros de Cidadania LGBT, uma questão que de início já se apresentava referia-se ao modo como captamos esses movimentos, sem aprisioná-los. Neste sentido, Uziel sinaliza que "se nós pensarmos nas questões de diversidades sexuais e de gênero, na questão da pluralidade da diversidade sexual, nós nos colocamos esse desafio" (2011, p. 24).

Conceber esta equipe enquanto uma máquina produtora de sentidos e subjetivações nos remete a engrenagens relacionadas ao engajamento técnico-político e à perspectiva clínico-política com os quais os profissionais desta equipe técnica construíam sua atuação. Entendemos a máquina, neste contexto produtor, enquanto algo que faz oposição à estrutura quando "associada a um sentimento de eternidade, ao passo que a máquina implica uma relação de emergência, de finitude, de destruição e de mortes" (Guattari, 2012, p. 68), que segue, então produzindo sentidos e novos mundos.

Pensar no processo criativo que envolve as práticas produzidas no Centro de Cidadania LGBT corresponde a apostarmos em uma prática política produtora de novos sentidos e novas subjetivações, que seja um devir, um agenciamento, uma multiplicidade de possibilidades que comporte termos heterogêneos e que estabeleça ligações e conexões entre idades, sexos e reinos, como sugerem Deleuze e Parnet (2004). O cotidiano também comporta as limitações deste serviço e desta política, porém assumimos aqui a sua potencialidade micropolítica e as implicações daquilo que nos afetam.

Os corpos das pessoas LGBT e, consequentemente, suas lutas, tensões, violações, desafios e enfrentamentos nos possibilitam pensar sobre as muitas encrencas, como propõe Azerêdo (2010), que surgem no campo da diversidade sexual e de gênero, quando novos modos de vida vão criando fissuras em um modelo hegemônico, colocando em xeque o sistema que se fundamenta na heterossexualidade e no binarismo de gênero.

No Centro de Cidadania LGBT, local de encrenca e de (re)construção de corpos, éramos convocados a repensar intervenções, apontando para uma direção mais política e potencializadora das práticas clínicas. Neste sentido, Passos e Barros (2009) sinalizam a importância da "possibilidade de pensar o campo da clínica nisso que ele tem de potência de se criar e recriar a cada instante" (2009, p. 103), concepção que muito se aproxima das práticas que vínhamos construindo e realizando nos Centro de Cidadania LGBT.

Pensar na equipe técnica enquanto uma máquina produtora de sentidos, de mundo e de subjetividade nos remete a pensar acerca da potência que existe nas práticas e na própria vida, o que nos obrigava a ruir com qualquer muro que pudesse se apresentar em nossas práticas. E todas essas práticas eram construídas no coletivo, fosse a equipe interdisciplinar na ponta, o compartilhamento das intervenções com os(as) usuários(as) ou os encontros regulares com a Equipe de Psicologia na UERJ da qual fazíamos parte também. As reuniões transcorriam de um modo leve e transparente, sempre contando com alguns quitutes gastronômicos que compartilhávamos e que, para além de nos nutrir fisicamente, eram momentos de formação de vínculos e troca de afetos. Aprendemos, pensamos, compartilhamos e nos tornamos outros profissionais, de modo que podemos afirmar que todos estes espaços, práticas e possibilidades de intervenção aqui relatados assumiram a encrenca (Azerêdo, 2010) e a potência de vida em seu fazer, que se coloca, então, como possíveis refazeres ad infinitum.

\section{Referências}

Aguião, S. (2018). Fazer-se no "estado": Uma etnografia sobre o processo de constituição dos "LGBT" como sujeitos de direitos no Brasil contemporâneo. Rio de Janeiro, RJ: Universidade do Estado do Rio de Janeiro. 
Almeida, G. S., \& Murta, D. (2013). Reflexões sobre a possibilidade da despatologização da transexualidade e a necessidade da assistência integral à saúde de transexuais no Brasil. Sexualidad, Saludy Sociedad (Rio de Janeiro), (14), 380-407. https://doi.org/10.1590/S1984-64872013000200017

Alvarez, J., \& Passos, E. (2009). Cartografar é habitar um território existencial. In V. Kastrup, E. Passos, \& L. Escossia (Orgs.), Pistas do método da cartografia: Pesquisa-intervenção e produção de subjetividade (pp. 131-149). Porto Alegre, RS: Sulina.

Anderson, B. (2008). Comunidades imaginadas. São Paulo, SP: Companhia das Letras.

Azerêdo, S. (2010). Encrenca de gênero nas teorizações em psicologia. Revista Estudos Feministas, 18(1), 175-188. https://doi.org/10.1590/S0104-026X2010000100011

Bento, B., \& Pelúcio, L. (2012). Despatologização do gênero: A politização das identidades abjetas. Revista Estudos Feministas, 20(2), 559-568. https://doi.org/10.1590/S0104-026X2012000200017

Brasil. Ministério da Saúde. (2004). Brasil sem homofobia: Programa de combate à violência e à discriminação contra LGTB e de promoção da cidadania homossexual. Brasília, DF: o autor.

Campos, G. W. S. (2012). Apoio matricial e práticas ampliadas e compartilhadas em redes de atenção. Psicologia em Revista, 18(1), 148-168.

Carrara, S., Aguião, S., Lopes, P. V. L., \& Tota, M. (2017). Retratos da política LGBT no estado do Rio de Janeiro. Rio de Janeiro, RJ: Centro de Estudos e Pesquisa em Saúde Coletiva.

Cassal, L. C. B. (2018). Um estudo entre ruínas: O programa Rio sem homofobia e a política LGBT fluminense. Rebeh: Revista Brasileira de Estudos da Homocultura, 1(4), 124-162.

Coimbra, C. M. B., \& Nascimento, M. L. D. (2007). Sobreimplicação: Práticas de esvaziamento político. In E. M. M. Arantes, M. D. Nascimento, \& T. M. G. Fonseca (Orgs.), Práticas PSI inventando a vida (pp. 27-38). Niterói, RJ: Universidade Federal Fluminense.

Decreto No. 40.822, de 28 de junho de 2007. Constitui a Câmara Técnica para a elaboração do Programa estadual de combate à homofobia e promoção da cidadania da população de gays, lésbicas, bissexuais, travestis e transexuais e dá outras providências. Diário Oficial do Estado do Rio de Janeiro. 29 jun. 2007.

Deleuze, G., \& Parnet, C. (1997). Diálogos. São Paulo, SP: Escuta.

Guattari, F. (2012). Caosmose. São Paulo, SP: 34.

Foucault, M. (1979). Microfísica do poder. Rio de Janeiro, RJ: Graal.

Freire, L. (2016). Sujeitos de papel: Sobre a materialização de pessoas transexuais e a regulação do acesso a direitos. Cadernos Pagu, (48), 212-245. https://doi.org/10.1590/18094449201600480013

Jesus, J. G. (2016). Medicina: Uma ciência maligna? Debate psicopolítico sobre estereótipos e fatos. Periódicus, 1(5), 195-204. https://doi.org/10.9771/peri.vli5.17187

Passos, E., \& Barros, R. B. D. (2000). A construção do plano da clínica e o conceito de transdisciplinaridade. Psicologia: Teoria e Pesquisa, 16(1), 71-79. https://doi.org/10.1590/S0102-37722000000100010

.Resolução CFP No 1, de 29 de janeiro de 2018. Estabelece normas de atuação para as psicólogas e os psicólogos em relação às pessoas transexuais e travestis. Brasília, DF: CFP. Recuperado de https://site.cfp.org.br/wp-content/ uploads/2018/01/Resolu\%C3\%A7\%C3\%A3o-CFP-01-2018.pdf

Rocon, P. C., Sodré, F., Zamboni, J., Rodrigues, A., \& Roseiro, M. C. F. B. (2017). O que esperam pessoas trans do Sistema Único de Saúde? Interface: Comunicação, Saúde, Educação, 22(64), 43-53. https:// doi.org/10.1590/180757622016.0712

Teixeira, F. B. (2017). (Des)engano: Revisando as portarias do processo transexualizador no SUS. In A. P. Uziel, \& F. Guilhon (Orgs.), Transdiversidades: Práticas e diálogos em trânsitos (pp. 313-352). Rio de Janeiro, RJ: Universidade do Estado do Rio de Janeiro.

Uziel, A. P. (2011). Diversidade sexual, democracia e promoção de direitos. In Conselho Federal de Psicologia CFP, Seminário psicologia e diversidade sexual: Desafios para uma sociedade de direitos (pp. 13-24). Brasília, DF: o autor. 


\section{Flávio Guilhon}

Psicólogo. Professor colaborador na Universidade Unigranrio. Doutorando pela Universidade Federal Fluminense (UFF), Niterói - RJ. Brasil.

E-mail: guilhon.flavio@gmail.com

\section{Texto Retratado}

(iD) https://orcid.org/0000-0002-8407-1353

Aureliano Lopes da Silva Junior

Psicólogo. Professor do Centro Universitário de Valença (UNIFAA), Valença - RJ, Brasil.

\section{Texto Retratado}

E-mail: aurelianolopes@gmail.com

(iD) http://orcid.org/0000-0002-9872-9830

\section{Carolina Motta}

Psicóloga. Mestre em Psicologia pela Universidade Federal Fluminense (UFF), Niterói - RJ. Brasil.

Eexto Retratado
E-mail: hrimbrasil@gmail.com
iD http://orcid.org/0000-0002-4623-9637
Amanda Duarte Moura
Psicóloga Clínica. Mestra em Psicologia pela Universidade Federal Fluminense (UFF), Niterói - RJ. Brasil.
Texto Retratado

E-mail: amandadu.psico@gmail.com

iD http://orcid.org/0000-0001-7646-4846

\section{Anna Paula Uziel}

Professora associada da Universidade do Estado do Rio de Janeiro (UERJ), Rio de Janeiro - RJ. Brasil.

\section{Texto Retratado}

E-mail: uzilap@gmail.com

iD http://orcid.org/0000-0001-7807-3910

Endereço para envio de correspondência:

Universidade do Estado do Rio de Janeiro

Rua São Francisco Xavier 525/10 ${ }^{\circ}$ andar sala 10.017 F

20559-900

Recebido 12/09/2019

Aceito 04/10/2019

Received 09/12/2019

Approved 10/04/2019

Recibido 12/09/2019

Aceptado 04/10/2019 
Guilhon, F., Silva Junior, A. L.; Motta, C.; Moura, A. D.; Uziel, A. P. (2019). Centro de Cidadania LGBT: Memórias e Experiências.

Como citar: Guilhon, F, Silva Junior, A. L.; Motta, C.; Moura, A. D.; Uziel, A. P. (2019). Centro de Cidadania LGBT: Memórias e Experiências no Campo das Práticas Psi em Prol da Defesa dos Direitos Humanos. Psicologia: Ciência e Profissão, 39 (n.spe 3), 135-145. https://doi.org/10.1590/1982-3703003228604

How to cite: Guilhon, F., Silva Junior, A. L.; Motta, C.; Moura, A. D.; Uziel, A. P. (2019). LGBT citizenship center: memories and experiences in the field of psi practices for the defense of human rights. Psicologia: Ciência e Profissão, 39 (n.spe 3), 135-145. https://doi.org/10.1590/1982-3703003228604

Cómo citar: Guilhon, F., Silva Junior, A. L.; Motta, C.; Moura, A. D.; Uziel, A. P. (2019). Centro de ciudadanía lgbt: memorias y experiencias en el campo de las prácticas psi en defensa de los derechos humanos. Psicologia: Ciência e Profissão, 39 (n.spe 3), 135-145. https://doi.org/10.1590/1982-3703003228604 